\title{
Revisão Bibliográfica sobre Pesquisas com Livros Didáticos de Química: Análise das Funções Identificadas
}

\author{
A Meta-Analysis of Studies on Chemistry Textbooks and their Functions
}

Rafael Silva de Araujo, Bruno Silva Leite

Palavras-chave Resumo O Livro Didático de Química (LDQ) é um recurso bastante Livro Didático;

Química;

Revisão da utilizado no ambiente escolar, fazendo parte do planejamento e da prática do professor, contribuindo para o processo de ensino e Literatura. investigado se mostra pertinente. Neste sentido, realizamos uma revisão bibliográfica sobre como as produções acadêmicas vêm abordando o LDQ, correlacionando com as 4 funções (referencial, ideológica/cultural, instrumental e documental) que o livro didático pode assumir. Desse modo, uma pesquisa exploratória com abordagem qualitativa foi realizada em três etapas: investigação dos principais temas estudados sobre o LDQ no último decênio em periódicos; levantamento dos principais temas estudados sobre o LDQ nos três últimos anais do ENPEC e ENEQ; construção das categorias a priori fundamentadas na análise de conteúdo, a partir das funções do livro didático. A posteriori encontramos nove temas estudados nas produções científicas analisadas que se relacionam com as quatro funções. Os resultados revelam que dos 115 trabalhos analisados, pelo menos uma das quatro funções estava presente. Ademais, os dados apontam que a função referencial foi a que mais se apresentou em trabalhos publicados, em contrapartida a que teve menos trabalhos referidos foi a função documental. Por fim, este trabalho apresenta as características presentes nos LDQ e que pesquisas que abordam essas funções ainda são incipientes, indicando a importância desta pesquisa. 
Keywords Abstract The Chemistry Textbook(CT) is a resource that is often used Textbooks; in the classroom, being part of the planning and practice of the teacher,

Chemistry; and supporting teaching and learning processes. Understanding how Literature Review. this teaching resource has been investigated remains pertinent. In this sense, a bibliographical revision was made in order to assess how the CT has been approached, bearing in mind Choppin's (2004) four functions to textbooks - referential, ideological/cultural, instrumental, and documentary. This bibliographical study was divided into three parts: an investigation of the main topics studied about the CT in the last decade in scientific journals; a survey of the main topics studied about the CT in of the minutes of the last three editions of ENPEC and ENEQ; a system of categories based on content analysis, using the textbook functions. We found nine topics studied in the analyzed works that relate to the four functions mentioned. The results show that, in the 115 studies analyzed, at least one of the four functions was present. In addition, the data indicate that the referential function was the most prevalent among all the four, whilst the documentary function was the least mentioned. Finally, we conclude by presenting the characteristics found in the CTs, and highlight that research on these functions is still incipient.

\section{Introdução}

A sociedade do século XXI, nos últimos anos, vem passando por grandes mudanças em seus aspectos organizacionais macros e micros, que norteiam as suas dinâmicas sociais, políticas e dialógicas. Essas alterações vêm exigindo novos paradigmas de comportamento e atitudes das pessoas que vivem constantemente essas transformações. As exigências de novas competências (conhecimento, habilidade e atitude) são requisitos indispensáveis para uma sociedade que está em constante transformação, pois são necessárias pessoas que possam tomar certas decisões (individuais ou coletivas) para um melhor desenvolvimento da sociedade como um todo. Assim, podemos relacionar a esses novos requisitos, os quais são propostos para a educação pela nova Base Nacional Comum Curricular (BNCC), duas competências gerais para a educação básica das dez propostas no documento, como exemplo

2. Exercitar a curiosidade intelectual e recorrer à abordagem própria das ciências, incluindo a investigação, a reflexão, a análise crítica, a imaginação e a criatividade, para investigar causas, elaborar e testar hipóteses, formular e resolver problemas e criar soluções (inclusive tecnológicas) com base nos conhecimentos das diferentes áreas (Ministério da Educação, 2018, p. 9);

10. Agir pessoal e coletivamente com autonomia, responsabilidade, flexibilidade, resiliência e determinação, tomando decisões com base em princípios éticos, democráticos, inclusivos, sustentáveis e solidários (Ministério da Educação, 2018, p. 10). 
Entendemos que essas competências que a BNCC propõe, refletem diretamente na sala de aula, que é um espaço privilegiado de construção de conhecimentos, de atitudes e habilidades que o educando desenvolve para ser um cidadão preparado para as dinâmicas do mundo contemporâneo. Esse reflexo proporciona ao professor um papel importante de mediador desse desenvolvimento, pois assim desenvolve suas práticas, renovandoas para acompanhar as dinâmicas que o século XXI nos demanda. Considerando que "se estas práticas não são renovadas, os métodos, processos e conteúdos educacionais que conhecemos (e admiramos) se tornarão irrelevantes porque deixarão de atender a demanda do seu contexto" (Leite, 2018a, p. 581).

Desta forma, com o desenvolvimento dessas competências necessárias, o livro didático (LD) se torna um recurso importante no processo de ensino e aprendizagem, em que mantém seu espaço nos contextos sociais e adquire mais formas de "existir" e influenciar seu ambiente. Um desses ambientes é o escolar, em que o LD se faz presente em todos os sentidos, desde a produção, transformação, até a internalização dos conhecimentos científicos que esse material carrega, buscando uma linguagem mais acessível ao seu usuário e consumidor. Destarte, a própria prática do professor em sala de aula pode ser modificada, uma vez que o LD, quando alinhado à BNCC, valoriza o desenvolvimento de habilidades e competências em detrimento da simples memorização de conteúdos podendo auxiliar o professor na ampliação de sua capacidade de análise, reflexão e crítica acerca do seu trabalho. Cabe ressaltar que a proposta para o PNLD 2021 - Ensino Médio foi ancorada nas competências e habilidades elencadas na BNCC (Edital No 03/2019 - CGPLI, 2019).

Corroborando com a importância do LD no contexto escolar, Oliveira (2017) afirma que o material é emblemático e indispensável na organização curricular, produção de aula e otimização do tempo docente. Moretto (2017, p. 30) destaca que "o livro didático, enquanto importante ferramenta de trabalho do professor, deve oferecer atividades adequadas que permitam desenvolver habilidades de compreensão". Sousa (2017, p. 103) caracteriza o LD como "um importante recurso na organização e na sistematização do conhecimento", e que o LD "tem sido objeto de análise e reflexão da prática pedagógica" (Sousa, 2017, p. 103). Ademais, "o livro didático pode ser considerado hoje, no Brasil, um dos principais instrumentos de difusão, não só de métodos e conteúdos educativos, mas de informação e cultura" (Vitiello, 2017, p. 9). Além de se constituir como um recurso "que pode contribuir para promover tanto a formação dos educandos quanto o suporte pedagógico ao trabalho do professor" (Miranda \& Almeida, 2020, p. 18), em que seu uso no ambiente educacional encontra alternativas múltiplas de efetivação.

Compreendemos a importância desse recurso na atualidade, como difusor do conhecimento científico, pois o processo de construção de experiências atrelado a um material como o LD pode contribuir para a construção de uma sociedade mais justa e igualitária. Em vista disso, Freitag et al. (1997) afirmam que com o LD o ensino no Brasil é penoso, e que sem ele seria terrivelmente pior. Assim, sem mais esse material como um recurso de apoio às práticas docentes, para estes autores, o ensino brasileiro 
passaria por mais dificuldades do que já passa. Desta forma, devemos olhar para o LD como mais um recurso importante no processo de ensino e aprendizagem, pois o livro poderá ser de grande ajuda ao professor no seu planejamento e estratégias didáticas, podendo influenciar a construção de conhecimento dos conteúdos científicos. Segundo Theodoro et al. (2012), o LD "adotado pelo professor deveria ser uma das referências para o acesso ao conteúdo disciplinar da escola" (p. 163). Acreditamos que

O bom livro didático diferencia-se do livro didático ruim pelo tipo de diálogo que estabelece com o professor, durante o planejamento do curso. Não obstante, o livro didático bom, adequado e correto, também pressuponha que o professor personifique o uso que dele faz na sala de aula, o livro didático ruim exige que o professor interfira de forma sistemática nos conteúdos e atividades propostos e considerados inadequados (Lajolo, 1996, p. 07).

Segundo Santos (2013), o LD "é considerado um dos principais recursos didáticos impressos, utilizados por professores e estudantes do sistema público de ensino" (p. 36). Já Basso e Terrazan (2015, p. 258), destacam que o LD é um "produto importante no cenário da educação brasileira pelo papel que desempenha na divulgação dos saberes socialmente legitimados das diferentes áreas do conhecimento", além disso o LD contribui na organização da atividade dos professores. No contexto brasileiro, Rosa e Artuso (2019) apontam que "o LD ainda possui relevante papel ao verificarmos que nem todas as escolas possuem computadores, acesso à internet [...]" (p. 713), o que lhe confere status de grande importância como um recurso didático.

Esse recurso didático assume uma complexidade pela qual poucos materiais didáticos podem se incumbir, pois sua inserção no espaço escolar envolve diversos aspectos e pessoas no seu trato, carregando uma bagagem de características que o LD - cheio de recurso e conteúdo - pode proporcionar a seus usuários. Deste modo, devemos enxergá-lo com "a complexidade do objeto livro didático, a multiplicidade de suas funções, a coexistência de outros suportes educativos e a diversidade de agentes que ele envolve" (Choppin, 2004, p. 552). Destaca-se que os LD podem assumir múltiplas formas em seu contexto escolar junto a seus usuários, havendo quatro funções que variam de acordo com "o ambiente sociocultural, à época, as disciplinas, os níveis de ensino, os métodos e as formas de utilização" (Choppin, 2004, p. 553). Nesse contexto, essas quatros funções se caracterizam como a:

1. Função referencial, na qual se exprime a ideia de currículo que ajuda a planejar as aulas e traz todo o conhecimento, técnicas e habilidades que se julgam necessárias ao aprendizado;

2. Função instrumental, que propõe as técnicas, aplicações de exercícios, introdução de componentes transversais ao conteúdo e resolução de problemas;

3. Função ideológica ou cultural, a qual suscita que existe a constituição de uma identidade nacional a partir da proposta que o LD apresenta, sendo assim um papel muito importante atribuído ao LD e ao mesmo tempo delicado; 
4. Função documental, em que o LD pode sugerir documento que proporcione um pensamento crítico do seu usuário privilegiando o desenvolver da iniciativa e autonomia do estudante e requer uma formação mais ampla do professor para que esses efeitos sejam efetivados em sala de aula e fora dela.

Destarte, entender qual função o LD pode assumir no contexto escolar permite compreender como este recurso está sendo abordado e/ou utilizado pela comunidade escolar, pois o LD apresenta possibilidades de uso que só o contexto em que está inserido poderá defini-lo. Nesse sentido, as funções apontadas por Choppin (2004) destacam que o LD pode apresentar várias características inerentes ao seu uso no processo de ensino e aprendizagem. Ademais, as funções (referencial, instrumental, ideológica cultural e documental) se tornam peças valiosas na compreensão da complexidade do livro didático de Química (LDQ) e suas nuances na construção do conhecimento científico junto aos estudantes e professores.

No Brasil o LDQ, com o passar dos anos, foi ganhando cada vez mais espaço como recurso importante no processo de ensino e aprendizagem do estudante, pois hoje esse material se caracteriza como um elemento natural no ambiente de construção do conhecimento. O LDQ passou por grandes transformações ao longo do seu tempo de existência se caracterizando como um recurso educacional de extrema importância, sendo utilizado como um meio de transformações políticas, sociais e ideológicas (Freitag et al., 1997).

A partir da virada do milênio, os livros didáticos começaram também a ser distribuídos para o Ensino Médio por meio do Programa Nacional do Livro Didático para o Ensino Médio (PNLEM), até então eram distribuídos para o primeiro ciclo da Educação Básica. O PNLEM buscava a universalização dos livros didáticos para os estudantes do ensino médio no Brasil. Nesse período, começaram a ser incluídos gradativamente os livros de Física, Biologia, Química, Sociologia, entre outros, na política do livro didático de todo o país (Turin, 2013). Destarte, começou-se a observar uma melhora e uma maior abrangência desses recursos disponibilizados para as escolas, professores e estudantes, assim podendo se criar uma cultura de escolha mais consciente pelos principais atores nesse processo de seleção do LD. Concordamos que

O Programa Nacional do Livro Didático tem aperfeiçoado o processo de avaliação dos Livros Didáticos, entretanto dentre todos os atores envolvidos com a escolha dos livros encontra-se o professor, o qual deve fazer a sua escolha a partir da análise crítica, como da busca pelo livro que melhor contemple tanto o Projeto Pedagógico da escola quanto ao aluno que receberá as obras didáticas (Turin, 2013, p. 29).

Com a reformulação do Programa Nacional do Livro Didático (PNLD), os livros passaram a ser escolhidos pelos professores que lecionavam o componente curricular referente ao LD, acontecendo assim a democratização da escolha desse material, pois antes as escolhas não passavam pelo crivo dos principais mediadores desse recurso didático (Cassiano, 2014; Gramowski et al., 2017). O LDQ passou a ser distribuído 
integralmente no ano de 2008, em que teve os primeiros exemplares disponibilizados para os professores analisarem e selecionarem o livro mais adequado para a sua realidade escolar. Deste modo

A partir do ano de 2007, todas as regiões passam a ser atendidas pelo Programa e as disciplinas vão sendo gradualmente inseridas para a escolha das obras. Com a universalização do Programa, todos os alunos do Ensino Médio passam a ser beneficiados com a ampliação da distribuição de livros didáticos também para as disciplinas de Química e História (Turin, 2013, p. 23).

Assim com o aperfeiçoamento dessa política pública o programa tem como objetivo selecionar e melhorar a qualidade do livro didático na Educação Básica, além de possibilitar que o LDQ se configure como mais um dos recursos para o desenvolvimento do trabalho em sala de aula.

Em vista disso, o cotidiano do estudante deve ser trabalhado junto do ambiente escolar que é abrangido por diversos recursos educacionais os quais podem melhorar e contribuir para uma formação significativa do estudante. O LDQ faz parte desses recursos que vêm contribuindo para a formação tanto do estudante como do professor, pois se compõe do conhecimento científico sistematizado em uma linguagem mais acessível e de fácil compreensão pelos atores envolvidos no processo de aprendizagem, proporcionando um encontro entre a ciência, estudantes e o professor, podendo desta forma, relacionar seu dia a dia com o que é aprendido em sala de aula. Para Carvalho (2009) "é indispensável discutirmos sobre o papel do livro didático como recurso de leitura influenciador da prática de ensino na sala de aula, pelos professores, e da aprendizagem de conceitos, pelos alunos" (p. 14). Compreende-se que o LDQ pode

[...] auxiliar os/as docentes na construção de estratégias didático-pedagógicas para o seu ensino. No caso da Química, os livros didáticos apresentam conceitos, procedimentos e informações sobre a ciência, a tecnologia, o ambiente, a indústria, entre outros (Fundo Nacional de Desenvolvimento da Educação, 2017, p. 10).

Percebe-se que o uso do LDQ pode proporcionar grandes benefícios para aprendizagem do estudante e no trabalho docente, podendo assim, ser usado de várias formas que tragam um ensino voltado para aprendizagem científica e relacione o cotidiano do estudante com a ciência trazida pelo livro, proporcionando a alfabetização científica desse estudante. Entende-se que "a alfabetização deve desenvolver em uma pessoa qualquer a capacidade de organizar seu pensamento de maneira lógica, além de auxiliar na construção de uma consciência mais crítica em relação ao mundo que a cerca" (Sasseron \& Carvalho, 2011, p. 61).

Por outro lado, o professor não deve se apoiar completamente no LDQ como um recurso que vai nortear suas atividades integralmente, mas deve perceber que esse material é um complemento para suas aulas com seus estudantes no processo de construção do conhecimento. Assim, o LD em algumas escolas “[...], infelizmente, não é tratado como um complemento. Ele é um elemento tão presente na sala de aula quanto 
o próprio professor. Alguns deles proíbem os alunos de entrarem na sala de aula por não terem trazido o livro didático" (Bunzen, 2000, p. 2). O professor não deve ser refém de um recurso didático, mas deve atrelá-lo às suas atividades de ensino e aprendizagem como um reforço para priorizar a aprendizagem dos estudantes, devendo proporcionar o uso do LDQ de uma forma integradora nessa construção com seus alunos. A aula deve ser compreendida como um momento de encontro entre o professor e seu estudante, tornando-se um espaço de troca de conhecimentos, em que o estudante possa realizar seus sonhos e desejos e se torne uma pessoa mais segura de si nas suas relações interpessoais (Garcia, 1997).

Assim, como parte de uma pesquisa de mestrado, realizamos uma análise de trabalhos publicados envolvendo o estudo sobre LDQ correlacionando com as quatro funções (referencial, instrumental, ideológica/cultural e documental) caracterizadas por Choppin (2004) para o LD.

\section{Metodologia}

Com o objetivo de realizar uma análise a partir de uma revisão bibliográfica sobre como as produções acadêmicas vêm abordando o LDQ, correlacionando com as quatro funções que o LD pode assumir apontadas por Choppin (2004), realizouse uma pesquisa exploratória a partir do levantamento nas bases de dados do Google Acadêmico, Portal Scielo, Portal de periódicos Capes no último decênio (2009 a 2019) e nas três últimas edições de dois eventos científicos: Encontro Nacional de Pesquisa em Ensino de Ciência - ENPEC (nos anos de 2015, 2017 e 2019) e Encontro Nacional de Ensino de Química - ENEQ (realizado nos anos de 2014, 2016 e 2018). A escolha destes dois eventos se justifica por serem considerados importantes pela comunidade de educadores químicos. Segundo Oliveira (2010), uma revisão bibliográfica consiste em

Analisar documentos de domínio científico, tais como livros, enciclopédias, periódicos, ensaios críticos, dicionários e artigos científicos e com a principal finalidade de levar o pesquisador a entrar em contato direto com obras, artigos ou documentos que tratem do tema estudado (Oliveira, 2010, p. 69).

Segundo Triviños (1987), a pesquisa exploratória vem com a perspectiva principal de permitir ao pesquisador "aumentar sua experiência em torno de determinado problema. O pesquisador parte de uma hipótese e aprofunda seu estudo nos limites de uma realidade específica, buscando antecedentes e maior conhecimento para uma pesquisa” (p. 109). Já Oliveira (2010) traz a perspectiva do estudo exploratório como algo que serve para "dar uma explicação geral sobre determinado fato, através da delimitação do estudo, levantamento bibliográfico, leitura e análise de documentos" (p. 65). Portanto, esse tipo de estudo ajuda a dar uma visão geral do objeto de estudo em foco. Em regra, o estudo exploratório é utilizado quando o tema escolhido de estudo é pouco explorado - no nosso caso, a presença das quatro funções do LD em publicações acadêmicas sobre os LDQ - sendo constituído o primeiro passo da pesquisa. 
Nesse sentido, como critério de busca das produções acadêmicas, foi usado o descritor livro didático de Química para gerar os resultados sobre trabalhos que abordem apenas esse recurso didático, considerando o período de 10 anos (2009 a 2019) para as bases de dados que englobam as publicações em revistas e os três últimos anais de dois eventos (ENPEC e ENEQ). Optamos por esse período por acreditarmos que abarca um número considerável de trabalhos mais atuais sobre o LDQ. Em relação à base de dados das publicações dos periódicos acrescentamos mais um critério na escolha dos artigos, sendo analisados nesta pesquisa apenas os periódicos que são classificados com Qualis A1, A2 e B1 pela avaliação quadrienal (quadriênio 2013-2016) do Qualis-periódicos CAPES.

O desenvolvimento da pesquisa foi realizado em três etapas. Na primeira etapa realizamos o levantamento dos principais temas estudados sobre o LDQ no último decênio em periódicos com Qualis A1, A2 e B1 nas bases de dados do Google Acadêmico, Portal Scielo e Portal Periódico Capes. A segunda etapa consistiu no levantamento dos principais temas estudados sobre o LDQ nos 3 últimos anais do ENPEC (nas edições de 2015, 2017 e 2019) e do ENEQ (nas edições de 2014, 2016 e 2018). Para ambas as etapas, a análise foi baseada inicialmente pela leitura dos títulos dos trabalhos e em seguida dos resumos (dos arquivos encontrados nas bases) e quando não percebíamos a temática abordada no estudo ao ler o resumo, partíamos para a leitura integral do trabalho para identificar a que tema ele pertencia.

Na terceira etapa utilizamos os princípios da análise de conteúdo na perspectiva de Bardin (2016) para criar categorias a priori, onde são elementos que surgem à parte de estudos teóricos para correlacionar com os dados encontrados durante as análises do material em questão. Conforme Bardin (2016), as categorias são rubricas ou classes que agrupam elementos em função de características comuns, com isso, para a autora, categorizar envolve a investigação do que cada um dos elementos tem em comum. Nesse contexto, apresentamos as categorias a priori originárias do estudo de Choppin (2004) destacando que os LD podem assumir quatro funções no contexto escolar junto a seus usuários. A Figura 1 apresenta as categorias a priori e suas descrições. 
Figura 1. Categorias a priori das funções presentes no $L D$

\begin{tabular}{|c|c|}
\hline Categoria a priori & Descrição \\
\hline Função Referencial & $\begin{array}{l}\text { Chamada de curricular ou programática, desde que existam programas de } \\
\text { ensino. O livro didático é apenas a fiel tradução do programa ou, quando se } \\
\text { exerce o livre jogo da concorrência, uma de suas possíveis interpretações. } \\
\text { Mas, em todo o caso, ele constitui o suporte privilegiado dos conteúdos } \\
\text { educativos, o depositário dos conhecimentos, técnicas ou habilidades que } \\
\text { um grupo social acredita que seja necessário transmitir às novas gerações. }\end{array}$ \\
\hline $\begin{array}{l}\text { Função Ideológica/ } \\
\text { Cultural }\end{array}$ & $\begin{array}{l}\text { A partir do século XIX, com a constituição dos estados nacionais e com o } \\
\text { desenvolvimento, nesse contexto, dos principais sistemas educativos, o livro } \\
\text { didático se afirmou como um dos vetores essenciais da língua, da cultura e } \\
\text { dos valores das classes dirigentes. Instrumento privilegiado de construção } \\
\text { de identidade, geralmente ele é reconhecido, assim como a moeda e a } \\
\text { bandeira, como um símbolo da soberania nacional e, nesse sentido, assume } \\
\text { um importante papel político. Essa função, que tende a aculturar - e, } \\
\text { em certos casos, a doutrinar - as jovens gerações, pode se exercer de } \\
\text { maneira explícita, até mesmo sistemática e ostensiva, ou, ainda, de maneira } \\
\text { dissimulada, sub-reptícia, implícita, mas não menos eficaz. }\end{array}$ \\
\hline $\begin{array}{c}\text { Função } \\
\text { Instrumental }\end{array}$ & $\begin{array}{l}\text { O livro didático põe em prática métodos de aprendizagem, propõe } \\
\text { exercícios ou atividades que, segundo o contexto, visam a facilitar a } \\
\text { memorização dos conhecimentos, favorecer a aquisição de competências } \\
\text { disciplinares ou transversais, a apropriação de habilidades, de métodos de } \\
\text { análise ou de resolução de problemas etc. }\end{array}$ \\
\hline Função Documental & $\begin{array}{l}\text { Acredita-se que o livro didático pode fornecer, sem que sua leitura } \\
\text { seja dirigida, um conjunto de documentos, textuais ou icônicos, cuja } \\
\text { observação ou confrontação podem vir a desenvolver o espírito crítico do } \\
\text { aluno. Essa função surgiu muito recentemente na literatura escolar e não } \\
\text { é universal: só é encontrada - afirmação que pode ser feita com muitas } \\
\text { reservas - em ambientes pedagógicos que privilegiam a iniciativa pessoal } \\
\text { da criança e visam a favorecer sua autonomia; supõe, também, um nível de } \\
\text { formação elevado dos professores. }\end{array}$ \\
\hline
\end{tabular}

Fonte: Choppin (2004, p. 553).

A partir dessa categorização a priori, perpetramos uma análise dos trabalhos encontrados para correlacionar essas funções com o que foi proposto nas pesquisas encontradas acerca do LDQ. A análise foi baseada na leitura dos resumos dos trabalhos encontrados, desta forma podemos apontar em qual categoria o trabalho se relaciona. Ainda nesta etapa, elencamos os principais temas (a posteriori) estudados nas produções científicas sobre o LDQ, que emergiram a partir da análise de conteúdo, sendo eles: (1) experimentação (EXP); (2) formação de conceitos (FC); (3) análise do conteúdo do LDQ (AC); (4) concepções docentes sobre o LDQ (CD); (5) abordagem histórica no LDQ (AH); (6) processo de escolha do LDQ (PE); (7) prática docente (PD); (8) o uso do LDQ (UL); (9) revisões sobre o LDQ (RL). 


\section{Resultados e discussões}

Nesta seção, apresentamos os resultados referentes às funções que o LDQ pode assumir no contexto escolar, sendo descrito a partir dos trabalhos encontrados no levantamento e das categorias elencadas nesta revisão bibliográfica. De forma geral, em nossa pesquisa, encontramos um número expressivo de trabalhos que fazem menção ao LDQ (em periódicos e nos eventos citados) sendo um total de 115 publicações. A Tabela 1 aponta os trabalhos encontrados por categoria e as quantidades. Cabe ressaltar que as categorias indicadas nesta tabela emergiram (a posteriori) da leitura dos trabalhos por meio da análise de conteúdo (Bardin, 2016).

Tabela 1. Quantitativo de trabalhos por temas encontrados em revistas e anais de eventos

\begin{tabular}{lcc}
\hline \multicolumn{1}{c}{ Categoria (a posteriori) } & $\begin{array}{c}\text { Quantidade de trabalhos } \\
\text { encontrado em revista } \\
(\mathbf{2 0 0 9} \mathbf{a ~ 2 0 1 9 )}\end{array}$ & $\begin{array}{c}\text { Quantidade de } \\
\text { trabalhos encontrado } \\
\text { no ENPEC e ENEQ }\end{array}$ \\
\hline Análise do conteúdo do LDQ (AC) & 12 & 33 \\
Formação de conceitos (FC) & 08 & 14 \\
Processo de escolha do LDQ (PE) & 06 & 09 \\
Abordagem histórica no LDQ (AH) & 04 & 06 \\
Experimentação (EXP) & 04 & 06 \\
O uso do LDQ (UL) & 02 & 03 \\
Revisões sobre o LDQ (RL) & 02 & 01 \\
Prática docente (PD) & 01 & 01 \\
Concepções docentes sobre o LDQ (CD) & 00 & 03 \\
\multicolumn{1}{c}{ Total } & 39 & 76 \\
\hline
\end{tabular}

Fonte: Autoria própria.

A partir destes dados, realizamos uma análise considerando as quatro funções que o LD pode assumir no contexto escolar, baseando-nos em Choppin (2004), observando quais funções estão presentes nos LDQ. Devido à restrição do número de páginas para um artigo de revista, optou-se por apresentar três trabalhos representativos de nossa análise, para cada uma das categorias elencadas na Figura 1. Ademais, selecionamos os trabalhos mais recentes (publicados nos anos 2017, 2018 ou 2019) para serem apresentados durantes as discussões, por considerarmos que estes podem refletir em informações mais atuais sobre como as funções estão sendo abordadas.

$\mathrm{Na}$ perspectiva de traçar um perfil desses trabalhos, realizou-se uma análise relacionando os temas com as funções propostas por Choppin (2004). Os dados revelaram que a função referencial é a que mais aparece nos artigos analisados. A função referencial foi a categoria com maior número de trabalhos encontrados nas pesquisas sobre o LDQ, sendo um total de 71 artigos, seguido da função ideológica cultural com 22 artigos, da função instrumental com 13 artigos e da função documental com 09 artigos. Dos dados do Gráfico 1, observa-se que em todos os 115 trabalhos analisados, 
pelo menos uma das quatro funções estava presente. Ademais, os dados revelam que os temas Análise de Conteúdo e Formação de Conceitos foram os que mais tiveram trabalhos, respectivamente 45 e 22 artigos, que se relacionavam com as quatro funções que o LD pode assumir.

A seguir, apresentamos como as produções científicas abordam o LDQ e como este assume uma função característica proposta por Choppin (2004).

\section{Função Referencial}

A função referencial traz a perspectiva de um LDQ conectado com o currículo ou programa escolar, pois segundo Choppin (2004) ele é um suporte de conhecimento, de técnicas e habilidades que o professor e o estudante podem adquirir para elevar seus conhecimentos científicos sobre a realidade em que estão inseridos, assim podendo transformá-lo em algo necessário para um convívio harmonioso entre seus pares. De um total de 115 publicações encontradas que têm como objeto de estudo o LDQ, 61,7\% (71 publicações) se categorizaram em relação função referencial definida por Choppin (2004). Nesse sentido, apresentam-se três trabalhos que estudaram o LDQ e se aproximaram da função referencial, ou seja, entende que o livro está inserido no contexto escolar e pedagógico, proporcionando inovações e melhorias no processo de ensino e aprendizagem dos estudantes.

O primeiro trabalho descrito apresenta o título "Ensino de Química e Letramento Científico: análise dos livros didáticos do PNLD” e faz parte do tema FC elencados durante o levantamento das pesquisas sobre o LDQ. Os autores Vaz, Bispo e Lacerda (2019) apresentam o objetivo de analisar a abordagem do letramento científico nos conteúdos de termoquímica nos LDQ do Programa Nacional do Livro Didático (PNLD) no período de 2008 a 2018. Para a coleta dos dados, foi utilizada a análise documental a partir de categorias elaboradas pelos autores. A análise indica que a maioria dos textos apresentados nos LDQ são dos próprios autores e poucos textos são de fontes e gêneros textuais variados. As representações do letramento científico em alguns LDQ se apresentaram de forma mais elucidativa e em outros de maneira superficial. Assim os autores, desse artigo, entendem que "a leitura, a compreensão dos textos e os exercícios, quando bem norteados, propiciam melhor articulação entre o conhecimento científico e a práxis social do educando" (Vaz et al., 2019, p. 09).

Desta maneira, trabalhar o LDQ de uma forma que desperte no estudante a curiosidade de compreender e internalizar o conhecimento científico é uma ação que pode provocar mudanças significativas em seu modo de enxergar o contexto social no qual está inserido. Choppin (2004) aponta que a função referencial carrega o contexto de transmitir técnicas e habilidades importantes para os estudantes, assim, atrelar essa função ao currículo ou ao programa escolar possibilita compreender que habilidade e técnicas de um grupo social são construídas e discutidas durante o processo escolar, além de trabalhar estas de forma consciente e objetiva determinando o contexto em que o estudante vai desenvolver seus conhecimentos e atitudes. 
Já o trabalho de Bego et al. (2019), intitulado "Qualidade dos livros didáticos de química aprovados pelo programa nacional do livro didático: análise do tema Estrutura da Matéria e Reações Químicas" faz parte da temática AC. Assim, o trabalho vem com o objetivo de avaliar o conteúdo e a abordagem dos temas estrutura da matéria e reações químicas em quatro LDQ aprovados pelo PNLD. A análise foi realizada utilizando o instrumento produzido por Furió e Domínguez (2007). A partir do que foi analisado os autores concluíram que os LDQ

apresentam conteúdo e abordagem bastante adequados, sobretudo à não veiculação de graves erros ou imprecisões conceituais e à diferenciação dos aspectos fenomenológico, teórico e representacional do conhecimento químico, com a delimitação da validade dos níveis de estudo macro e submicroscópico (Bego et al., 2019, p. 120).

Deste modo, a pesquisa concluiu que oslivros analisados apresentam uma melhoria na qualidade dos assuntos abordados em relação às últimas edições, proporcionando assim um melhor aproveitamento dos conteúdos apresentados pelos LDQ, tanto pelo professor quanto pelos estudantes. Ademais, com a melhora dos conteúdos dos LDQ o conhecimento científico passa a ser abordado no contexto escolar, pois Choppin (2004) afirma que, na função referencial, o LD constitui o suporte privilegiado de conteúdo educativo, em que o estudante junto com as orientações do professor pode desenvolver seus conhecimentos e habilidades aprendendo o que é trazido nesse recurso didático. Nesse sentido, o livro reforça seu papel importante em sala de aula, pois deve ser um elemento estruturador da prática docente e da aprendizagem dos estudantes (Garcia \& Bizzo, 2010).

A pesquisa de Cedran et al. (2016) traz como título "Reflexões sobre os critérios para seleção dos livros didáticos de Química no PNLD" e está relacionada com o tema PE. Essa pesquisa apresenta o objetivo de analisar os critérios eliminatórios contidos nos PNLD publicados em 2007, 2012, 2015 e 2018, para os LDQ. Desta forma, a partir da análise, os autores perceberam que ao longo das publicações (do PNLD) o número de critérios de escolha aumentou de quatro para onze e apresentavam mais critérios específicos de escolha dos livros pela comunidade escolar. A pesquisa aponta que com o aumento desses critérios é possível ter um olhar para livros que abordam temas atuais e considerados relevantes para os estudantes, como por exemplo, a educação ambiental (sendo um tema transversal no currículo escolar).

Nas conclusões, os autores apontam que esse aumento dos critérios ao longo dos anos buscou melhorar o processo de ensino e aprendizagem dos estudantes e disponibilizar materiais aos docentes que possibilitassem um uso mais significativo em seu trabalho na educação básica. Destarte, o LDQ apresenta cada vez mais critérios de escolha e aborda mais temas contemporâneos, o que acaba se tornando um recurso repleto de conhecimentos científicos, sendo uma das características apontadas por Choppin (2004) para a função referencial. 
Com o currículo atualizado para as questões que permeiam a sociedade atual, o LDQ se torna um difusor de atitudes e práticas que podem favorecer a solução de problemas que marcam o nosso século, tanto para as gerações atuais e como para as futuras gerações. Compreende-se, a partir dos escritos de Choppin (2004), que o livro se situa nas múltiplas interações, por vezes conflituosas, entre os agentes e os usuários. Segundo Maia e Villane (2016), o LDQ se constitui em um "instigante recurso didático para o professor e para o estudante, conferindo-lhe uma sensação de segurança" (p. 122). Entretanto, é preciso ter cuidado para que o LDQ não os engessem numa rotina que dificulte o exercício de sua criatividade e autonomia.

Os trabalhos descritos com a função referencial apresentam estudos de como o LDQ vem sendo compreendido em certos aspectos curriculares em um processo de ensino e aprendizagem, apresentando algumas abordagens dos assuntos trabalhados na educação básica. Choppin (2004) aponta que os livros são um suporte privilegiado de conteúdos educativos presente no dia a dia dos professores, acreditando que seja necessário na construção dos conhecimentos científicos dos estudantes e das futuras gerações.

\section{Função Ideológica ou cultural}

Segundo Choppin (2004) o livro didático assume um papel de transformador de opiniões, sendo seus aspectos usados para transformar a realidade do usuário desse material. O autor afirma que o LD assume um papel de vetor essencial da língua, da cultura e dos valores das classes dirigentes, ganhando um status privilegiado de construção de identidade política, social e cultural. Nesse sentido, nas publicações encontradas (115 artigos), um total de 22 publicações que estudaram o LDQ se categorizaram na função ideológica ou cultural, sendo referente a 19,1\% do total de trabalhos encontrados.

O trabalho de Rosa e Lambach (2018) com o título "Os livros didáticos de química e a resistência às mudanças no estilo de pensamento", fazendo parte da temática PE, vem com a intenção de fazer uma reflexão de caráter epistemológico acerca do processo de seleção dos LDQ, com o objetivo de revelar a existência de um padrão recorrente na escolha desses materiais. Segundo os Rosa e Lambach (2018) é de fundamental importância "se entender melhor o processo para a seleção dos LDQ, para que se torne um ato consciente, de natureza social e política, fundamentado principalmente nas necessidades dos estudantes" (p. 174). Esse estudo associou 04 características presentes na escolha dos professores, sendo elas: (1) relação entre o valor de venda da obra e sua seleção pelos professores; (2) adequações da obra às demandas dos editais de seleção; (3) conteúdos estruturantes dos LDQ no PNLD de 2008 a 2015; (4) a relação entre a estrutura de conteúdos e o padrão de escolha do LDQ. Escolher um LDQ que não está de acordo com o que o ambiente escolar precisa, é negar um processo de aprendizagem mais amplo e duradouro na vida dos estudantes, pois trazer material que transforme realidade do seu usuário é poder proporcionar um crescimento político, social e cultural na vida do estudante e dos seus familiares. 
O trabalho de Rosa e Lambach (2018) evidencia o que Choppin (2004) compreende quando o LD assume um caráter privilegiado de construção de identidades, se tornando um símbolo nacional que está presente no dia a dia escolar e no processo de ensino e aprendizagem. Nesse sentido, o processo de aquisição desse material para o contexto escolar deve ser compreendido como um todo para que suas características sejam entendidas e dessa forma, desenvolver uma cultura de escolhas adequadas ao contexto em que a escola está inserida, privilegiando a identidade que cada escola carrega. Nesse contexto, "é preciso levar em conta a multiplicidade dos agentes envolvidos em cada uma das etapas que marca a vida de um livro escolar, desde sua concepção pelo autor até seu descarte pelo professor" (Choppin, 2004, p. 553), o que corrobora com as pesquisas realizadas sobre o $\mathrm{LD}$, que o consideram como

um objeto de estudo altamente complexo e envolve agentes e usuários em uma cadeia que vai desde a elaboração, fabricação, autorização, modos de difusão, financiamento, procedimentos de seleção até a utilização do material (Garcia \& Bizzo, 2010, p. 16).

O trabalho de Assis e Vaz (2020), "Ensino de química e cidadania: análise dos livros didáticos de química do programa nacional do livro didático" contido na categoria AC, apresenta algumas características e informações sobre a abordagem de Cidadania nos conteúdos de termoquímica dos livros didáticos de Química do PNLD de 2008 a 2018, sendo os resultados divididos em 3 tópicos: (1) abordagem da história da ciência; (2) abordagem da educação ambiental; (3) abordagem multicultural.

Assis e Vaz (2020) entendem que o LDQ tem um papel fundamental nas mudanças de comportamento da sociedade e que o livro não pode ser silenciado ou neutro e nem adotar um modelo elitista e desigual, enfatizando que a "Química pode e deve ter um papel importante nesta área, pois pode mobilizar discussões tanto na área científica, quanto nas questões sociais (Assis \& Vaz, 2020, p. 220). Observa-se que a função ideológica e cultural descrita por Choppin (2004) é enfatizada no trabalho de Assis e Vaz (2020) em que o LDQ assume um importante papel político no contexto de construção da identidade humana, uma vez que ele pode contribuir para diminuir a desigualdade social e fortalecer o pensamento de que todos somos iguais e as distinções pela cor da pele, raça ou etnia, são características inerentes de cada indivíduo. A ciência é construída pela contribuição de todos e não pelo valor que a sociedade determina para cada pessoa. De maneira geral, o LD carrega em seu bojo as potencialidades de poder diminuir as desigualdades que acontecem dentro de um contexto escolar, de modo que ele seja

Considerado um elemento cultural ou ideológico, servindo, dentre outras coisas, para a unificação nacional e para a uniformização linguística, constituindo-se num instrumento de poder que influencia crianças e adolescentes, na medida em que os livros didáticos são reproduzidos e distribuídos em todo o território de um país (Garcia \& Bizzo, 2010, p. 16). 
Assim, essa forma de "ver o mundo" vem sendo carregada no "discurso politicamente correto dos livros - que apenas insere no campo visual pessoas brancas e não brancas, mas não problematiza os modos de produção do racismo" (Oliveira, 2017, p. 16) continuando a perpetuar a ordem racista vigente.

O trabalho "O enredo da experimentação no livro didático: construção de conhecimentos ou reprodução de teorias e verdades científicas?” de Güllich e Silva (2013) vinculado ao tema EXP, buscou analisar os experimentos contidos nos LDQ para avançar na discussão das interfaces que esses exercem na produção conceitual de práticas pedagógicas, de ideologias e na produção de sentido nas ciências e em seu ensino. O trabalho utilizou a análise documental analisando 10 livros, dividindo em categorias temáticas para análise. Os resultados apontam que na maioria dos livros analisados, a ciência se apresenta com uma visão reproducionista, pois dos 10 livros analisados, 09 se apresentaram dessa forma. Assim, Güllich e Silva (2013) entendem que "os equívocos teóricos e procedimentais corroboram sobremaneira a reprodução de teorias e verdades científicas, ideia discutida neste artigo. Essa dimensão leva a uma visão de ciência distorcida e à produção de falsas verdades" (p. 164). Os discursos presentes nos livros através dos seus conteúdos analisados, segundo a pesquisa, se apresentam de forma autoritária, fortalecendo a visão simplista do docente e o positivismo lógico como concepção de ciência presentes nos LDQ. Desta forma, concordamos com Piassi et al. (2009), quando apresentam o ponto de vista ideológico que

um discurso que se afina a ideia de ciência de resultados. A atividade científica, para ser legitima, tem que produzir soluções a problemas pré-determinados. Fazer ciência nesse contexto não e especular, teorizar ou questionar e sim produzir soluções eficientes (Piassi et al., 2009, p 15).

Entende-se que proporcionar visões da Ciência de uma forma não progressista pode causar prejuízo à evolução científica em um contexto político, social e cultural, pois entender ciência de forma positiva é se manter dentro de uma visão restrita sem "observar o que está a sua volta de uma forma natural". Assim, a função ideológica/ cultural proposta por Choppin (2004) é observada no trabalho, uma vez que o LD pode ter características de aculturar - e, em certos casos, a doutrinar - as jovens gerações quando este, no nosso caso o LDQ, não constrói ambientes de reflexões e pensamentos do que está ao redor do leitor, formando um sujeito que não analisa sua realidade e nem vivencia questões que estão fora do seu contexto cultural e político. Além disso, não problematizar os textos no LDQ traz o significado que as estruturas de poder que privilegiam certa parcela da sociedade, que permanecem intocadas e que fazem parte do processo de ensino e aprendizagem dos estudantes, não tomam frente de combater essas construções sociais e políticas, assim retrocedendo no combate à depreciação do ser humano pelas suas particularidades e individualidades (Oliveira, 2017). 


\section{Função Instrumental}

Nos estudos de Choppin (2004) entende-se que a função instrumental define o LD como um manual contendo instruções que "visam a facilitar a memorização dos conhecimentos, favorecer a aquisição de competências disciplinares ou transversais, a apropriação de habilidades, de métodos de análise ou de resolução de problemas, etc." (Choppin, 2004, p. 553). A partir do levantamento foram encontrados 13 trabalhos que se categorizaram nessa função, representando $11,3 \%$ do total.

O trabalho de Leite (2018b) intitulado "A experimentação no ensino de química: uma análise das abordagens nos livros didáticos" faz parte da temática EXP e apresenta o objetivo de analisar os tipos de atividades experimentais nos LDQ. A pesquisa foi de cunho exploratória com análise documental sendo analisadas 05 coleções de livrostexto de química totalizando 15 exemplares. Dessa análise, foram encontrados 183 experimentos nos livros e categorizados em 06 tipos de atividades experimentais, sendo elas empírico-indutivista; demonstrativas; ilustrativas; investigativas; conceituais e técnicas. Os resultados dessa pesquisa demonstram que a maioria dos livros analisados têm os experimentos voltados para as categorias empírico-indutivistas e demonstrativas, sendo categorias que prezam a experimentação como comprovação de fatos e teorias, levando em conta apenas a observação e a descoberta como principal foco, trazendo poucos experimentos voltados para as categorias investigativas, conceituais e técnicas (Leite, 2018b).

Nesse contexto, as características dos LD apresentadas por Leite (2018b) se aproximam da função instrumental, que para Choppin (2004), os LD tendem a carregar as características de um livro voltado para facilitar a memorização dos conhecimentos. Os LDQ que sustentam a reprodução de experimentos (quer seja empírico-indutivista ou demonstrativa), apenas para comprovar certos fenômenos, contribuem para que se perpetuem as práticas ditas tradicionais e, dessa forma, os estudantes se tornam apenas reprodutores de conhecimento já pronto e acabado. Assim, "em outras palavras, uma visão de ciência externa, neutra, quantitativa, empírica, gera no ensino e na aprendizagem uma visão de sujeito isento/neutro, que reproduz de forma passiva o que lhe é apresentado" (Güllich \& Silva, 2013, p. 156).

O trabalho "Os livros didáticos e o PNLD: um olhar sobre a experimentação e a gestão de resíduos" de Silva e Philippsen (2017), pertencente à temática EXP, apresenta a proposta de investigar os Guias dos Livros Didáticos (GLD) das edições do PNLD 2012 e 2015 para a disciplina de Química com foco nos critérios estabelecidos para a experimentação e para a gestão de resíduos presentes nos LDQ. Foi realizada a leitura do GLD para selecionar os livros para a análise, selecionando-se 07 livros de química para observar como as atividades experimentais então sendo tratadas nesses livros. A pesquisa permitiu visualizar que os LDQ apresentam experimentos que podem ser adaptados às características demonstrativos-investigativos, podendo propor perguntas iniciais aos estudantes para desenvolvimento dos experimentos. Silva e Philippsen (2017) apontam que "quase todos os livros analisados utilizam os mesmos produtos químicos perigosos 
em suas atividades experimentais" (p. 08). Nesse sentido, os resultados da pesquisa mostram que "nem todos os livros avaliados e aprovados pelo PNLD 2015 estão de acordo com os critérios relacionados à experimentação” (Silva \& Philippsen, 2017, p. 8).

Choppin (2004) aponta uma característica importante presente na função experimental do LD relacionada ao desenvolvimento de métodos de análise ou de resolução de problemas, em que a partir de propostas experimentais os estudantes desenvolvem suas habilidades para solucionar problemas propostos nas atividades, junto com o professor mediando as situações adversas que se apresentam. Destarte, LDQ que apresentam experimentos que desenvolvam essas habilidades, podem contribuir de forma significativa para o desenvolvimento dos estudantes e suas habilidades de resolução de problemas, proporcionando assim um crescimento científico.

Por fim, o trabalho de Rosalino et al. (2019) intitulado "Levantamento e análise dos experimentos de Química presentes nos livros do PNLD”, pertencente à temática EXP, apresentou um estudo que visou analisar os experimentos nos LDQ e determinar quais as principais e mais comuns temáticas presentes. A análise se baseou na abordagem sistemática de cada livro, com o intuito de tabelar os experimentos e assim organizar as temáticas de cada um. Os resultados mostraram que nos 06 livros estudados, foram encontrados um total de 237 experimentos que em sua maioria são voltados para área de físico-química e química geral, sendo respectivamente 73 e 60 experimentos cada. Os temas mais trabalhados nos experimentos no tópico físico-química, encontrados durante a análise, são a termoquímica e propriedade dos gases e nos experimentos no tópico química geral é o estudo da química das substâncias. Os autores concluem que

As áreas de Química Orgânica/Química Ambiental/Bioquímica e Química Analítica possuem menos experimentos, entretanto com temáticas mais variadas, buscando uma maior contextualização científica e educacional, uma vez que os experimentos abordados não se enquadram como cotidianos, principalmente nos que abordam QOAB. Ficou claro também que, a área de Química Orgânica é a que possui menos atividades práticas, concentrando o conteúdo na teoria (Rosalino et al., 2019, p. 6).

Observa-se nesta pesquisa outra característica apontada por Choppin (2004) para a função instrumental, a de favorecer a aquisição de competências disciplinares ou transversais, em que a partir do que foi proposto no experimento, os estudantes adquirem competências, habilidades e atitudes relacionadas ao contexto de suas vidas (cotidiano contextualizado experimentalmente), sendo desenvolvidas durante todo seu percurso escolar. Ademais, entender como esses temas transversais se correlacionam com o cotidiano através dos experimentos proporciona uma visão de mundo para a conscientização de que temas sensíveis estejam relacionados aos acontecimentos do nosso dia a dia. Assim, Choppin (2004) identifica que "se os temas abordados são múltiplos, eles revelam, em cada país, preocupações comuns e recorrentes, ou então questões relacionadas a determinados acontecimentos localizados em determinado tempo e espaço (Choppin, 2004, p. 556). 
Desta forma, compreende-se que os trabalhos apresentados na função instrumental estudam como os experimentos são abordados nos LDQ e como estes vêm evoluindo ao longo do tempo. Percebe-se que as pesquisas mostram que a experimentação ainda é vista como reproducionista, que os experimentos são vivenciados apenas para a confirmação de algo ou observação de algum fenômeno químico e mesmo com a evolução do programa voltado para o LDQ, muitos exemplares deixam a desejar nos seus conteúdos. Todavia, alguns LDQ trazem propostas significativas de experimentação para serem trabalhadas em sala de aula, experimentos que propõem atividade investigativa, de resolução de problemas e que ajudam a desenvolver competências, habilidades e atitudes perante problemas do cotidiano. Os LDQ que apresentem essas características devem ser abarcados pelas escolas, pois as escolas têm a função de preparar os estudantes para solucionar os problemas que afetam a sociedade e também preparar cidadãos para contribuir com sua comunidade de forma efetiva e permanente.

\section{Função Documental}

A função documental que o LD apresenta é caracterizada a partir do seu conteúdo, proporcionando um conjunto de documentos, textuais ou icônicos, que podem estimular o desenvolvimento do espirito crítico do estudante a partir das observações e confrontação de ideias. Um ambiente que favorece a iniciativa dos estudantes a serem protagonistas no processo de construção do conhecimento é um lugar favorável para que o LD possa proporcionar o desenvolvimento do senso crítico e assim realizar os objetivos pretendidos no desenvolvimento escolar (Choppin, 2004).

Em relação à função documental, apenas 09 artigos foram identificados com as características desta função, representando um percentual de 7,8\% do total de trabalhos que estudaram os LDQ como seu objeto de pesquisa. Embora esta função assinale que o livro didático pode proporcionar ao estudante um estudo mais autônomo e ativo a partir do seu conteúdo, percebe-se que poucos trabalhos se categorizam em relação a essa função, pois estimular a iniciativa dos estudantes não é tarefa fácil em um ambiente no qual predominam as atividades ditas tradicionais em comparação com as atividades que podem criar um ambiente de processos autônomos dos estudantes e mediados pelo professor.

A pesquisa de Francisco Junior e Lima (2013), com o título “Considerações acerca da leitura em livros didáticos de química: uma análise a partir de textos complementares" foi categorizado na temática UL e apresenta o objetivo de investigar alguns aspectos apresentados por textos complementares em LDQ, como número, fontes e atividades propostas. Os LDQ selecionados estavam presentes no PNLD, sendo 06 livros analisados. Em seguida, realizou-se a identificação dos livros e dos textos complementares em cada livro, estabelecendo-se os critérios de avaliação: (1) a quantidade de textos e aspectos textuais; (2) fonte e natureza dos textos e; (3) tipos de atividades propostas. A pesquisa conclui que 
A presença quantitativa dos textos é um destaque positivo na maior parte das obras. Como já mencionado, os textos complementares são uma importante ferramenta da qual dispõe os professores para trazer à sala de aula outros tipos de textos que não os didáticos. Todavia, maior diversidade de gêneros e fontes seria importante para um enriquecimento da atividade pedagógica do professor. Além disso, com exceção de uma obra, as estratégias de leitura propostas pouco favorecem um processo ativo e crítico de leitura, que considere o seu papel interativo e sociocognitivo (Francisco Junior \& Lima, 2013, p. 494).

Nesta perspectiva, na função documental os LD apresentam uma caraterística em comum, sendo "um conjunto de documentos, textuais ou icônicos, cuja observação ou confrontação podem vir a desenvolver o espírito crítico do aluno" (Choppin, 2004, p. 553), como observado no trabalho de Francisco Junior e Lima (2013). Ademais, verificouse que nos trabalhos analisados o LDQ deveria incluir atividades de leituras variadas, estimulando o processo criativo dos estudantes e aspectos ligados ao desenvolvimento ativo deles (Choppin, 2004).

O trabalho de Silva e Cintra (2019) trazendo como título "Análise gráfica nos livros didáticos de Química do PNLD 2018-2020 - Um estudo de caso" inserido na temática FC, apresenta o objetivo de analisar as representações gráficas dispostas em livros de Química aprovadas no PNLD 2018-2020, considerando a presença de elementos que são essenciais na estrutura de um gráfico e as finalidades que essas representações podem assumir no texto. A análise foi de cunho qualitativo, classificando as representações e atribuindo pontuações para cada um dos critérios alcançados de acordo com os referenciais utilizados. Os resultados indicam que as representações gráficas, presentes nos LDQ analisados na pesquisa citada, variaram em torno de $50 \%$, $43 \%$ e $68 \%$ nos três livros da coleção analisada. O volume 03 (que aborda os conteúdos de química orgânica) foi o que mais apresentou representações em seu conteúdo. Silva e Cintra (2019) concluem que

$\mathrm{Na}$ coleção estudada, observa-se que há uma grande utilização dessas representações no contexto de exercícios, sem uma conexão direta com o conteúdo conceitual apresentado. No que se refere ao conteúdo conceitual, propriamente dito, a obra apresenta um equilíbrio entre as finalidades explicativa e exposicional, apresentando num primeiro momento um fato científico e depois sua devida explicação, o que contribui para uma aprendizagem mais significativa dos conceitos estudados (Silva \& Cintra, 2019, p. 6).

De forma geral, a função documental, ou seja, aqueles que tratam dos documentos, textos e imagens presentes nos livros, observa-se que os LD trazem várias formas de textos e uma delas são os gráficos, que têm um papel fundamental no processo de ensino e aprendizagem. Nessa perspectiva, Coutinho et al. (2010), reforçam a ideia de que é importante compreender como se dá o uso de textos e imagens nos $\mathrm{LD}$, uma vez que a má compreensão desses podem levar a um planejamento inadequado pelos professores que 
utilizam esse recurso didático. A utilização desses aspectos icônicos presentes nos LDQ incentiva o seu uso como um recurso complementar, favorecendo o trabalho pedagógico e o planejamento do professor (Choppin, 2004). Neste contexto, corroborando com a percepção de que a utilização dos gráficos como mecanismo de aprendizado e que são elementos que se adequam ao que a função documental explicita, entende-se que

As formas de representação são imprescindíveis na construção de significados e sentidos, posto que, utilizando-se as representações gráficas como base de uma ideia ou conceito, é possível interpretar a realidade por meios e formas de expressão distinta. O próprio pensamento pode tornar-se mais explícito e consciente em função das características gráficas que reduzem a sua complexidade e a abstração, contribuindo para o alcance da essência da ideia que se deseja transmitir, simplificando, dessa forma, sua comunicação e compreensão (Pereira \& Núñes, 2013, p. 2).

No trabalho de Cinha e Vasconcelos (2019), a utilização de imagens para aprendizagem do estudante a partir de tirinhas cômicas presentes no LDQ são discutidos. Esse trabalho apresenta o título "Análise descritiva a partir de tiras cômicas em uma coleção de livros didáticos de Química” e está presente na categoria FC. Esse trabalho tinha como objetivo analisar as possíveis contribuições que os quadrinhos, encontrados em uma coleção de LDQ da Educação Básica aprovado no PNLD 2012, poderiam ter como recurso colaborativo no processo de ensino e aprendizagem desta disciplina. A pesquisa é de cunho qualitativo e foi realizada uma análise descritiva das tirinhas presentes no conteúdo dos LDQ estudados. Os resultados apontam que existe um total de 119 tirinhas distribuídas na coleção analisada. Do total de tirinhas analisadas, 50 tinham relação direta e 11 não apresentavam nenhuma informação com o conteúdo explorado, mostrando que algumas tirinhas, presentes no LDQ, eram colocadas apenas para ilustração sem um fator educacional por trás desse conteúdo.

Assim, Choppin (2004) entende que o uso desses recursos visuais pode contribuir para o desenvolvimento do pensamento e senso crítico dos estudantes, pois a visualização dos assuntos de outras maneiras pode colaborar para a construção do conhecimento por parte dos estudantes, uma vez que favorece a diversificação das formas de como o conteúdo de química pode ser apresentado. Consequentemente, produzir um LDQ que efetivamente apresente esse recurso - a tirinha cômica - e que traga orientações consolidadas para o professor trabalhar em sala de aula, não é trivial, pois demanda muitas pesquisas para encontrar a melhor forma de elaborar o LDQ pertinente às múltiplas realidades brasileiras.

A partir da função documental, considerando os pressupostos de Choppin (2004), compreende-se que o LDQ tem um papel fundamental no processo de ensino e aprendizagem dos estudantes, pois o processo de aquisição de conhecimentos atrelado à realidade científica, através da exposição das múltiplas representações presentes nos LDQ, deve ser trabalhado de forma consciente pelos professores para que seus estudantes não saiam com as informações erradas ao utilizarem os livros. Nesse sentido, 
produzir um LDQ com os critérios necessários para essa apropriação é de fundamental importância tanto para o trabalho dos professores, como para a aprendizagem dos estudantes. Assim, esses recursos, os documentos textuais ou icônicos, podem ajudar a amenizar as dificuldades que os estudantes apresentam durante as atividades realizadas em sala de aula ou fora dela, pois esses recursos desempenham um papel fundamental no processo de ensino e aprendizagem dos estudantes e, se utilizados de forma adequada, podem auxiliar na compreensão de muitos conceitos abstratos e por vezes estranhos para os estudantes (Silva et al., 2013). Para Basso e Terrazzan (2015), os professores, dentre os diversos critérios para seleção do LD, "escolhem os LD conforme as imagens que possuem sobre seus alunos, considerando a linguagem utilizada no livro, os tipos de textos apresentados, os recursos gráficos, etc." (p. 270).

\section{Conclusões e implicações}

Esta pesquisa teve como objetivo analisar, nos trabalhos acadêmicos do último decênio que tiveram o LDQ como objeto de estudo, a presença das quatro (04) funções do LD propostas por Choppin (2004). Observou-se que dos 115 trabalhos investigados, a Função Referencial foi a que mais esteve presente, apresentando um total de 71 publicações, representando $61,7 \%$ do total de trabalhos encontrados e a função com menos trabalhos foi a Função Documental com um total de 09 publicações, equivalendo a $7,8 \%$ do total.

No que diz respeito à análise dos trabalhos, foi possível verificar que esses apresentam as características das funções do LD indicadas por Choppin (2004). Em relação à Função Referencial observou-se que há um interesse dos pesquisadores sobre estudar como o LDQ se comporta em relação ao currículo escolar ou programas de ensino, sendo a maioria das pesquisas voltadas para os aspectos de como o LDQ pode ajudar no processo de ensino e aprendizagem dos estudantes. A Função Instrumental está presente nos trabalhos analisados envolvendo instruções que enfatizam a memorização dos conhecimentos mostrando que a maioria dos LDQ apresenta a experimentação para confirmar algo já pronto. Além disso, observa-se que poucos livros trazem a perspectiva de experimentos investigativos e para a resolução de problemas, uma vez que podem contribuir para o desenvolvimento das competências dos estudantes. Na Função ideológica ou cultural é perceptível nos trabalhos investigados que há um movimento para entender como o LDQ está inserido nas mudanças culturais, políticas e sociais, e como este material está presente no contexto escolar. Já na Função Documental, apresenta trabalhos que evidenciam a perspectiva de um ensino que desenvolva o senso crítico dos estudantes a partir das informações complementares apresentadas em seu conteúdo (como conjunto de documentos, textuais ou icônicos, etc.), prevalecendo o uso do LDQ atrelado ao desenvolvimento do senso crítico e da autonomia do estudante.

Compreende-se que os estudos sobre o LDQ são importantes, pois esses recursos didáticos acompanham as mudanças ocorridas nas escolas (quer seja política ou pedagógica) e contribuem para o processo de ensino e aprendizagem da Química. Desta 
forma, com o olhar que Choppin (2004) apresenta sobre as 04 funções que um o LD pode assumir no contexto escolar, entende-se haver mais uma forma de compreender como esse recurso didático pode contribuir para uma formação duradoura e efetiva dos estudantes, principais usuários desse material. Ademais, os resultados desta análise apontam para maior colaboração nos estudos sobre o LDQ fortalecendo o seu entendimento como recurso presente e natural no contexto escolar, bem como desperta uma nova forma de análise do livro didático de Química.

Assim, estudos sobre a análise das funções que o LD pode assumir contribui na compreensão desse material e como ele se adéqua na ação dos professores em suas aulas. Os professores podem estabelecer estratégias de construção pedagógica, ensino e aprendizagem com seus estudantes, com o objetivo de facilitar o uso do LDQ, alinhadas com as funções do LD. Pesquisas futuras que levem à promoção destas funções, no momento, se configuram como importantes para auxiliar no uso mais consciente do LDQ. Além disso, pesquisas que abordam essas funções do LD no contexto escolar ainda são escassas no ensino das Ciências.

Diante do que foi apresentado neste texto, lança-se a questão: as funções (referencial, ideológica/cultural, instrumental e documental) que podem ser assumidas por um LD influenciam ou contribuem no planejamento, prática e escolha do LDQ pelos professores? As respostas podem gerar desdobramentos para outras questões, por exemplo: Quantas funções podem ser observadas no livro didático de Química? Como o conhecimento sobre essas funções possibilitam melhorias no processo de ensino e aprendizagem? Com a implementação da BNCC, estas funções serão impactadas?

Ao encerrar as ideias expostas aqui, a partir deste recorte de uma pesquisa de mestrado, acredita-se que os dados analisados podem contribuir para o avanço dos debates sobre o LDQ no Brasil considerando os pressupostos de Choppin (2004) e que novos estudos, considerando as funções do LD, possam colaborar com o entendimento desse material didático presente no contexto escolar, político e social de estudantes e professores.

\section{Agradecimentos}

À Coordenação de Aperfeiçoamento de Pessoal de Nível Superior - CAPES. Ao Programa de Pós-Graduação em Ensino de Ciências e Matemática - PPGEC. Aos avaliadores deste artigo pelas importantes contribuições no avanço deste estudo.

\section{Referências}

Assis, N. R. B., \& Vaz, W. F. (2020). Ensino de química e cidadania: análise dos livros didáticos de química do programa nacional do livro didático. Revista Virtual de Química, 12(1), 196-222. http://dx.doi.org/10.21577/1984-6835.20200016

Bardin, L. (2016). Análise de conteúdo. Edições 70. 
Basso, L. D. P., \& Terrazzan, E. A. (2015). Organização e realização do processo de escolha de livros didáticos em escolas de educação básica. Revista Eletrônica de Educação, 9(3), 256-272. http://dx.doi.org/10.14244/198271991210

Bego, A. M., Suart Júnior, J. B., Prado, K. F., \& Zulian, S. R. Q. A. (2019). Qualidade dos livros didáticos de química aprovados pelo programa nacional do livro didático: análise do tema Estrutura da Matéria e Reações Químicas. Revista Electrónica de Enseñanza de Las Ciencias, 18(1), 104-123.

Bunzen, C. (2000). O tratamento do conceito de gramática nos livros didáticos. Ao pé da letra, 2(1), 1-8.

Carvalho, A. M. P. (2009). Ensino de ciências e matemática II: temas sobre a formação de conceitos. Editora UNESP.

Cassiano, C. C. D. F. (2014). O mercado do livro didático no Brasil do século XXI. Editora UNESP.

Cedran, D. P., Cedran, J. C., \& Kiouranis, N. M. M. (25-29 de julho, 2016). Reflexões sobre os critérios para seleção dos livros didáticos de Química no PNLD. XVIII Encontro nacional de ensino de química, Florianópolis, Santa Catarina.

Choppin, A. (2004). História dos livros e das edições didáticas: sobre o estado da arte. Educação e Pesquisa, 30(3), 549-566.

Cinha, J. O. S, \& Vasconcelos, F. C. G. (25-28 de junho, 2019). Análise descritiva a partir de tiras cômicas em uma coleção de livros didáticos de Química. XII Encontro Nacional de Pesquisa em Educação em Ciências, Natal, Rio Grande do Norte.

Coutinho, F. A., Soares, A. G., Braga, S. A. M., Chaves, A. C. L., \& Costa, F. J. (2010). Análise do valor didático de imagens presentes em livros de Biologia para o ensino médio. Revista Brasileira de Pesquisa em Educação em Ciências, 10(3).

Francisco Junior, W. E. F., \& Lima, S. P. (2013). Considerações acerca da leitura em livros didáticos de química: uma análise a partir de textos complementares. Educación Química, 24(2), 489-494. http://dx.doi.org/10.1016/S0187-893X(13)72518-7

Freitag, B., Costa, W. F., \& Motta, V. R. (1997). O livro Didático em Questão. Cortez.

Fundo Nacional de Desenvolvimento da Educação (FNDE) (2017). PNLD 2018: Química - guia de livros didáticos. http://www.fnde.gov.br/pnld-2018/

Furió, C., \& Domínguez, M. C. (2007). Deficiencia en la enseñanza habitual de los conceptos macroscópicos de sustancia y de cambio químico. Journal of Science Education, $8(2), 84-92$.

Garcia, O. G. (1997). A aula como momento de formação de educandos e educadores. Revista de educação, 104, 62-84. 
Garcia, P. S., \& Bizzo, N. (2010). A pesquisa em livros didáticos de ciências e as inovações no ensino. Educação em Foco, 13(15), 13-35. https://doi.org/10.24934/eef.v13i15.89

Gramowski, V. B., Delizoicov, N. C., \& Maestrelli, S. R. P. (2017). O PNLD e os guias dos livros didáticos de ciências (1999-2014): uma análise possível. Ensaio Pesquisa em Educação em Ciências, 19, e2571. https://doi.org/10.1590/1983-21172017190110

Güllich, R. I. C., \& Silva, L. H. A. (2013). O enredo da experimentação no livro didático: construção de conhecimentos ou reprodução de teorias e verdades científicas?. Ensaio Pesquisa em Educação em Ciências, 15(2), 155-167. https://doi.org/10.1590/198321172013150210

Lajolo, M. (1996). Livro didático: um (quase) manual de usuário. Em Aberto, 16(69), 3-9.

Leite, B. S. (2018a). Aprendizagem Tecnológica Ativa. Revista Internacional de Educação Superior, 4(3), 580-609. http://dx.doi.org/10.20396/riesup.v4i3.8652160

Leite, B. S. (2018b). Experimentação no ensino de química: uma análise das abordagens nos livros didáticos. Educación Química, 29(3), 61-78. http://dx.doi.org/10.22201/ fq.18708404e.2018.3.63726

Maia, J. O., \& Villani, A. (2016). A relação de professores de Química com o livro didático e o caderno do professor. Revista Electrónica de Enseñanza de las Ciencias, 15(1), 121 146.

Ministério da Educação (2018). Base Nacional Comum Curricular. http:// basenacionalcomum.mec.gov.br/images/BNCC_EI_EF_110518_versaofinal_site.pdf

Ministério da Educação (2019). Edital de convocação No 03/2019 - CGPLI. https:// www.gov.br/fnde/pt-br/acesso-a-informacao/acoes-e-programas/programas/ programas-do-livro/consultas-editais/editais/edital-pnld-2021/EDITAL_PNLD_2021_ CONSOLIDADO_13_RETIFICACAO_07.04.2021.pdf

Miranda, S. R., \& de Almeida, F. R. (2020). Passado, presente e futuro dos livros didáticos de História frente a uma BNCC sem futuro. Escritas do Tempo, 2(5), 10-38. https://doi. org/10.47694/issn.2674-7758.v2.i5.2020.1038

Moretto, M. (2017). O ensino da leitura no ensino fundamental: uma análise das questões de compreensão de texto. In M. Moretto (Org.), O livro didático na Educação Básica: múltiplos olhares (pp. 27-43). Paco Editorial.

Oliveira, M. M. (2010). Como fazer pesquisa qualitativa. Vozes.

Oliveira, R. M. (2017). Descolonizar os livros didáticos: raça, gênero e colonialidade nos livros de educação do campo. Revista Brasileira de Educação, 22(68), 11-33. https://doi. org/10.1590/s1413-24782017226802 
Pereira, J. E., \& Núñez, I. B. (10-13 de novembro, 2013). Gráficos cartesianos nos livros didáticos de Química do PNLD 2012. IX Encontro Nacional de Pesquisa em Educação em Ciências, Águas de Lindóia, São Paulo.

Piassi, L. P., Santos, E. I., Vieira, R. M. B., \& Ferreira, N. C. (2009). O discurso ideológico sobre Aristóteles nos livros didáticos de Física. Revista Brasileira de Pesquisa em Educação em Ciências, 9(2), 1-19.

Rosa, M. D., \& Artuso, A. R. (2019). O Uso do Livro Didático de Ciências de $6^{\circ}$ a $9^{\circ}$ Ano: Um Estudo com Professores Brasileiros. Revista Brasileira de Pesquisa em Educação em Ciências, 19, 709-746. https://doi.org/10.28976/1984-2686rbpec2019u709746

Rosa, T. F., \& Lambach, M. (2018). Os Livros Didáticos de Química e a Resistência às Mudanças no Estilo de Pensamento. Revista de Educação em Ciência e Tecnologia, 11(1), 173-193. https://doi.org/10.5007/1982-5153.2018v11n1p173

Rosalino, I., Silva, D. M., \& Kasseboehmer, A. C. (25-28 de junho, 2019). Levantamento e análise dos experimentos de Química presente nos livros do PNLD. XII Encontro Nacional de Pesquisa em Educação em Ciências, Natal, Rio Grande do Norte.

Santos, E. M. D. (2013). As representações sociais do livro didático por professores de matemática (Dissertação de Mestrado, Universidade Federal de Pernambuco, Recife, Pernambuco).

Sasseron, L. H., \& Carvalho, A. M. P. (2011). Alfabetização científica: uma revisão bibliográfica. Investigações em Ensino de Ciências, 16(1), 59-77.

Silva, D. L., \& Philippsen, E. A. (03-06 de julho, 2017). Os Livros Didáticos e o PNLD: um olhar sobre a experimentação e a gestão de resíduos. XI Encontro Nacional de Pesquisa em Educação em Ciências, Florianópolis, Santa Catarina.

Silva, G. B., \& Cintra, E. P. (25-28 de junho, 2019). Análise gráfica nos livros didáticos de Química do PNLD 2018-2020 - Um estudo de caso. XII Encontro Nacional de Pesquisa em Educação em Ciências, Natal, Rio Grande do Norte.

Silva, G. S., Braibante, M. E. F., \& Pazinato, M. S. (2013). Os recursos visuais utilizados na abordagem dos modelos atômicos: uma análise nos livros didáticos de química. Revista Brasileira de Pesquisa em Educação em Ciências, 13(2), 159-182.

Sousa, I. V. (2017). Gêneros textuais no livro da educação de jovens e adultos. In M. Moretto (Org.), O livro didático na Educação Básica: múltiplos olhares (pp. 103-121). Paco Editorial.

Theodoro, M. E. C., Kasseboehmer, A. C., \& Ferreira, L. H. (2012). Os aspectos sócioculturais e teórico-metodológicos recomendados pelo PCNEM: as contribuições dos livros didáticos de Química para os objetivos do Ensino Médio. Revista Brasileira de Pesquisa em Educação em Ciências, 11(2), 161-182. 
Triviños, A. N. S. (1987). Introdução à pesquisa em ciências sociais: a pesquisa qualitativa em educação. Atlas.

Turin, J. (2013). Livro didático de Química - PNLD/2012: fatores que influenciaram a escolha dos livros pelos professores da Educação Básica. (Dissertação de Mestrado, Universidade Federal do Paraná, Curitiba, Paraná). AcervoDigital da UFPR. https://hdl. handle.net/1884/34842

Vaz, W. S., Bispo, N. R., \& Larceda, K. A. P. (25-28 de junho, 2019). Ensino de Química e Letramento Científico: análise dos livros didáticos do PNLD. XII Encontro Nacional de Pesquisa em Educação em Ciência, Natal, Rio Grande do Norte.

Vitiello, A. M. (2017). Reflexões sobre as ações do estado e do mercado na produção de livros didáticos de geografia no Brasil. In M. Moretto (Org.), O livro didático na Educação Básica: múltiplos olhares (pp. 9-18). Paco Editorial.

\author{
Rafael Silva de Araujo \\ Universidade Federal Rural de Pernambuco \\ Recife, Pernambuco, Brasil \\ rafael.silva.araujo22@gmail.com \\ Bruno Silva Leite \\ Universidade Federal Rural de Pernambuco \\ Recife, Pernambuco, Brasil \\ brunoleite@ufrpe.br
}

Editora Responsável

Stefannie Ibraim

\footnotetext{
Manifestação de Atenção às Boas Práticas Científicas e de Isenção de Interesse

Os autores declaram ter cuidado de aspectos éticos ao longo do desenvolvimento da pesquisa e não ter qualquer interesse concorrente ou relações pessoais que possam ter influenciado o trabalho relatado no texto.
} 